\title{
25 Research Soure \\ Barriers to Condom Use Among Heterosexuals in Africa; the Niger Delta Case Study
}

\section{Dandison Nat Ebeh ( $\triangle$ mailnat2004@yahoo.com )}

Central Michigan University College of Health Professions https://orcid.org/0000-0002-3555-7146

Joseph $\mathbf{N}$ Inungu

Central Michigan University Herbert H and Grace A Dow College of Health Professions: Central Michigan University

College of Health Professions

\section{Tunde M Akinmoladun}

Central Michigan University Herbert H and Grace A Dow College of Health Professions: Central Michigan University College of Health Professions

Mark J Minelli

Central Michigan University Herbert H and Grace A Dow College of Health Professions: Central Michigan University College of Health Professions

\section{Research Article}

Keywords: Barriers, Condom use, Heterosexuals, Africa, Niger Delta, Case study

Posted Date: January 27th, 2022

DOI: https://doi.org/10.21203/rs.3.rs-1298837/v1

License: (c) (i) This work is licensed under a Creative Commons Attribution 4.0 International License. Read Full License 


\section{Abstract}

Introduction The search for an effective response and solution to the human immunodeficiency virus (HIV) / acquired immunodeficiency syndrome (AIDS) scourge continues to be of critical importance since the discovery of the first case in the United States in 1981. To date, in the absence of a known cure or vaccine, preventive and promotional measures remain a strategic measure to combating the menace. Objectives To identity barriers to condom use amongst heterosexuals in Africa, using the Niger Delta as a case study. Methodology This qualitative study was carried out using an online social media interactive medium. Ten experienced medical doctors from the Niger Delta subregion, recruited through a convenient snowballing technique, participated in the focus group discussion. Results Twelve elements were identified as barriers to condom use. They include poverty (worsened by environmental oil pollution), low and uneven distribution of knowledge and awareness, negative perception of condoms, impaired motivation, partner-related factors, lack of availability or access to a condom, religious factors, young age at first sexual debut affecting cognition to negotiate condom use, alcohol and substance use, intimate partner violence arising from gender inequality, cultural beliefs, social stigma, and accidental casual sex. Conclusion The findings of this study demonstrated the salient need for implementing a tailored health intervention program alongside the provision of public health measures. Awareness alone is not enough unless it translates into a behavioral change and control.

\section{Statement Of Problem}

The number of new HIV cases is declining worldwide, with reports of a 52\% reduction since its peak in 1997 (UNAIDS, 2021a). However, the global burden of HIV/AIDS is still on the rise, with an estimated 37.7 million people currently living with HIV/AIDS across the world, including 2.78 million children (WHO, 2021a; UNICEF, 2021). Sub-Saharan Africa accounting for a greater percentage of contributary burden (UNAIDS, 2021a; Kharsany \& Karim, 2016). In 2020, almost one million people died from HIV/AIDS-related causes, and it is estimated that about 2 million people become newly infected yearly (WHO, 2021a). Sadly, to date, HIV/AIDS remained a global public health scourge, and a leading cause of death as well as a development challenge in the African subregion. This is even with the introduction of condoms, a simple optimal device in preventive care, to fight this disease at both the individual and the community level (CDC, 2021). HIV/AIDS still constitutes an endemic disease in the African subregion causing an untold number of deaths and suffering following socioeconomic, ethnocultural, biological, and structural barriers to public health prevention strategies (Inungu \& Sarah, 2006).

\section{Background}

\section{Introduction}

The search for an effective response and solution to the human immunodeficiency virus (HIV) / acquired immunodeficiency syndrome (AIDS) scourge is of critical importance since the discovery of the first case in the United States in 1981 (CDC, 2006). To date, in the absence of a known cure or vaccine, preventive and promotional measures remain the only effective strategies to combating the HIV/AIDS scourge (Deek et al., 2016; UNAIDS, 2019a).

Health behaviors including, sexual abstinence, faithfulness to one sexual partner, use of condoms, and the use of pre or post-exposure antiretroviral drugs for HIV, constitute the current advocated position of the HIV experts (UNAIDS, 2019a), as well as early diagnosis and treatment as the mainstay in HIV/AIDS care. The virus is transmitted mostly through unprotected sexual contacts with infected persons, as well as through infected body fluids, the use of 
unsterilized sharp objects, and from mother to child transmission (WHO, 2020). This account for its widespread and ravaging impacts amongst sexually active persons and communities in Africa and beyond.

Sadly, of this knowledge of the various established preventive measures, particularly in the use of condoms (a sheath-shaped barrier device) known to be both effective in birth control and the prevention of sexually transmitted diseases (STDs), including HIV/ AIDS (CDC, 2021). challenges remain, in broad array of settings (UNAIDS, 2019a), commonly resulting from risky health behaviors, accrued from a mixed ethnocultural, socioeconomic, and religious behavioral representation (Fisher \& Fisher, 2000). All militating against the use of condoms as an effective behavioral health intervention tool to checkmating the AIDS epidemic, amongst heterosexuals in Africa. Therefore, necessitating the need for a behavioral change to risky sexual practices, the major focus being health education for safer sex, and promotion of appropriate and regular condom use (UNAIDS, 2019a).

\section{Aims/Objective}

This study aim is to identify barriers to condom use among heterosexuals in Africa (Nigeria's Niger Delta as case study) and thus make recommendations. Knowledge of these barriers will inform the design of effective intervention to discourage risky sexual behavior and practice. Findings will also help in the future design of a behavioral intervention program to effectively prevent and control the spread of the disease at the individual and community level. Thus, enhance preventive and promotional health amongst heterosexuals particularly in the Niger Delta and by extension Africa. This study will also help to provide baseline data for further studies and intervention.

\section{Assumptions}

For this study, it is assumed that being a medical doctor and practicing in the Niger Delta translates to having a critical and useful in-depth experience on the barriers to condom use and HIV prevention effort in the region. In addition, it is also assumed that participation in the study would be on participants' free will and responses would be as truthful as possible.

\section{Scope and Delimitations}

A potential delimitation for this study is the proposed geographic limit of the study (Niger delta context) as well as the choice of participants. Sequel to time, logistic and financial constraints, it would be impractical to survey every heterosexual in Africa.

Another delimitation of this study is the scope of the study, which uses online discussion forums of HIV/AIDS care doctors, and also providing an opportunity for a sort of round table discussion and deliberation of the HIV scourge in the region. Hence the use of critical stakeholders having prerequisite skills and experience as well as in the position to pass on research outcome to the community in the region.

\section{Limitations}

Focus group discussion studies are generally limited by being opinionated and prone to dominance by some socially accepted opinion or participants. Also, acquisition of participants through snowball technique could produce a narrow perspective to research. To address these, the proposed focus group acquired a neutral moderator for this study to help in the coordinating the discussion session. More so, the research objective was carried out using the 
Niger delta case study and via online discussion in accessing possible barriers eliminate challenge of study not been generalizable or lacking external validity.

\section{Significance}

This study is significant because it could help public health practitioners and healthcare professionals to gain new knowledge that could inform public health policy development, implementation and practice in addressing the HIV burden in Africa. Additionally, such knowledge could help develop targeted health education messages geared towards improving use of protective and preventive measures.

\section{Literature Review}

Despite the global efforts in the prevention and control of the HIV epidemics scourge, challenges persist, especially on the African continent, Nigeria's Niger Delta subregion inclusive (see Table ii, Table ii). This is a setback on advocated recommendations entailing promotional and preventive care intervention, such as sexual abstinence, fatefulness to one sexual partner, use of condoms, and the use of pre and/or post-exposure prophylaxis for HIV (UNAIDS, 2019a). The search for an effective solution to the HIV and AIDS pandemic continues to remain a top priority. As the HIV/AIDS most effective combating strategy continues to remain preventive and promotional healthcare, and because of the lack of a cure or vaccine (UNAIDS, 2019a). Various barriers associated with perceptions, attitudes, beliefs, and practices concerning HIV/AIDS prevention and control, constitute crucial factors in the burden of HIV/AIDS in the African region (Sovran, 2013). Furthermore, the lack of an effective health care delivery system is a barrier to HIV/AIDS prevention. Other factors such as social-economic status and lack of access to a health care facility for early diagnosis and treatments represent another barrier to HIV/AIDS prevention, globally (hiv.gov, 2020). In the Niger Delta region of Nigeria, HIV/AIDS is driven mostly by endemic structural problems and this includes poverty, gender inequality, unemployment, concurrent sexual partnerships, sexual exploitation, and forced migration (Udoh, 2009). Some potential barriers to HIV/AIDS prevention and treatment were said to be due to oil pollution and other environmental stressors (Udoh, 2013). The untoward effect of Oil exploration in the region worsened the HIV burden through the destruction of the livelihoods, institutions, and core values, which forces impoverished illiterate females to migrate or be trafficked to urban centers as sex workers (Udoh, 2013). The elevated HIV/AIDS risk in the Niger Delta brings into focus the mirage of contributory factors to the prevention and control of HIV/AIDS. Meanwhile, as evidenced from many texts, the most common means and routes of transmission continue to be majorly through unprotected sexual contact with infected persons accounting for widespread sustained impact amongst sexually active persons and communities in Africa and beyond (UNAIDS, 2019a). The other modes of transmission seen to be through contact with infected body fluids, use of infected sharp objects, and mother-to-child transmission. Thus, practical knowledge of the various established preventive measures, particularly the use of condoms known to be effective in birth control and prevention of sexually transmitted diseases (STDs), HIV/AIDS inclusive (UNAIDS, 2019a). The mixture of these ethnocultural, socioeconomic, and religious behavioral representations hamper the use of condoms in the African setting. Therefore, necessitating the need for behavioral change to risky sexual practices, the major focus being health education for safer sex, and the promotion of appropriate and regular condom use (UNAIDS, 2019). The HIV Prevalence by States and Geopolitical zone is hereby presented in Table i and Table ii respectively.

Table i. HIV Prevalence by States (UNAID, 2019b) 


\begin{tabular}{|l|l|}
\hline STATES & HIV PREVALENCE (\%) \\
\hline Akwa Ibom & 5.5 \\
\hline Benue & 5.3 \\
\hline Rivers & 3.8 \\
\hline Taraba & 2.9 \\
\hline Anambra & 2.4 \\
\hline Abia & 2.1 \\
\hline Cross River & 2.0 \\
\hline Enugu & 2.0 \\
\hline Nassarawa & 2.0 \\
\hline Bayelsa & 1.9 \\
\hline Delta & 1.9 \\
\hline Edo & 1.9 \\
\hline Imo & 1.8 \\
\hline Ogun & 1.6 \\
\hline Plateau & 1.6 \\
\hline FCT & 1.6 \\
\hline Lagos & 1.4 \\
\hline Gombe & 1.3 \\
\hline Adamawa & 1.2 \\
\hline Borno & 1.2 \\
\hline Kaduna & 1.1 \\
\hline Ondo & 1.1 \\
\hline Kwara & 1.0 \\
\hline Kogi & 0.9 \\
\hline
\end{tabular}




\begin{tabular}{|l|l|} 
Osun & 0.9 \\
\hline Oyo & 0.9 \\
\hline Ebonyi & 0.8 \\
\hline Ekiti & 0.8 \\
\hline Niger & 0.7 \\
\hline Kano & 0.6 \\
\hline Kebbi & 0.6 \\
\hline Bauchi & 0.5 \\
\hline Zamfara & 0.5 \\
\hline Sokoto & 0.4 \\
\hline Yobe & 0.4 \\
\hline Jigawa & 0.3 \\
\hline Katsina & 0.3 \\
\hline
\end{tabular}

Table ii. HIV Prevalence by Geopolitical Zones in Nigeria (UNAID, 2019b)

\begin{tabular}{|l|l|}
\hline ZONES & HIV PREVALENCE (\%) \\
\hline South-South & 3.1 \\
\hline North-Central & 2.0 \\
\hline South-East & 1.9 \\
\hline South-West & 1.1 \\
\hline North-East & 1.1 \\
\hline North-West & 0.6 \\
\hline
\end{tabular}

\section{Burden of Problem}


World over, HIV/AIDS remains the most prevalent threat to humans. Present on all continents, with an affectation cutting across all demographic strata, claiming many lives each year and with a predilection for the vulnerable poor, and underserved region of the world (Mathers and Loncar, 2006). The human immunodeficiency virus (HIV) has become one of the leading causes of death around the world today (UNAID, 2020). Globally, the burden of people currently living with HIV/AIDS is still unacceptably high. In 2015 it was estimated to be more than 35 million, today HIV affects an estimated 37.7 million people, including 2.78 million children (WHO, 2021a; UNICEF, 2021; WHO, 2021; Autenrieth et al. 2018). Most cases occurring in sub-Saharan Africa.

According to the United Nations program for HIV/AIDS (UNAIDS) in 2016, out of that estimate of 35 million, 19 million of them were from eastern and southern Africa, 6.5 million from western and central Africa. Furthermore, 5.1 million from Asia and the Pacific, 2.4 million from Western and Central Europe and North America, while Latin America and the Caribbean accounted for 2 million cases. Eastern Europe and Central Asia had 1.5 million and 230,000 cases were from the Middle East and northern Africa (UNAIDS, 2016). The World Health Organization also reported that HIV/AIDS continues to be a major global public health issue, accounting for record-high numbers of deaths, having claimed more than 32 million lives so far (WHO, 2021A). Due to hiatus in HIV care delivery, 770000 people died from HIV/AIDS-related causes in 2018, and about 2 million people were newly infected (WHO,2019). Over two-thirds of all people living with HIV (25.7 million) live in the WHO African Region (WHO, 2019). Even as HIV is prevalent amongst the general population in the region, an increasing number of new infections occur among key population groups.

\section{African Situation}

In the African context, a heterosexual relationship is the culturally accepted form of sexual behavior and practice. However, in many instances, this is devoid of condom use and cutting across the different strata of the reproductive age groups, following a host of limiting barrier factors earlier mentioned. This depending on peculiar situations, also comes with attendant public health challenges, asides from its reproductive benefits. Affecting a combination of health indices, socioeconomic life as well as regional and international implications.

According to the United Nations, the HIV epidemic situation varies among the 54 African countries across the continent. Though data on the prevalence of condom use has been inconsistent and limited (UNAIDS, 2019a; Statista.com, 2020). The prevalence of condom use was higher among sex works at $85.5 \%$ whereas that of non-sex workers was at 34\% (UNAIDS, 2021). A study carried out by Ayoola et al., (2014) saw condom use at the last sex act to be $65.9 \%$ but only $48.8 \%$ were said to be used consistently. The consequences of non-usage have been devastating, especially in the West, South, and East of the African continent (NAIDS, 2021; WHO, 2021). Sub-Saharan Africa represents the epicenter of the HIV/AIDS epidemic with more than $70 \%$ of all people living with HIV residing in the region (Kharsany \& Karim, 2016).

Compared to males, young women bear a disproportionate share of the HIV epidemic in South Africa with a staggering prevalence of $5.6 \%$ among those aged $15-19$ years and $17.4 \%$ among those aged $20-24$ years (Shisana 2012 et. al. as cited by Ntshiqa, T., et al. 2018). Heterosexual HIV transmission accounts for more than $90 \%$ of new HIV infections among sexually active people, most of which is attributed to not using a male condom (Ntshiqa, T., et al. 2018). In population-based surveys, countries that reportedly have higher use of condoms were seen to consistently report lower HIV prevalence when compared to countries that reported lower use of condoms (Sandøy et al. 2012; Sandøy et al. 2007; Reynolds et al. 2012). Also, in addition, an increase in male condom use in South Africa did play a critical role in the decline in HIV incidence that was witnessed between 2000 and 2008, highlighting a continued need to invest in male condom promotion and distribution (UNAIDS, 2015). Meanwhile, the use of female condoms by female partners were not popular, and faced two difficulties, the reaction of the woman's male partner 
and attitudes to the device itself (uneasiness using it). Although this was acceptable to female commercial sex workers, following that it offers them double protection (Deniaud, F.,1997) (Paz-Bailey et al. 2016).

More than 30 years after the first reported case of AIDS, Sub-Saharan Africa continues to be the most heavily afflicted region of the world. East and southern Africa alone account for $56 \%$ of the global burden of HIV with eight countries having estimates of more than 1,000,000 persons living with HIV/AIDS (Ntshiqa, T., et. al. 2018). Obstacles to the use of condoms in Africa remain a serious threat to the fight and global effort against the HIV/AIDS pandemic. Targeted efforts, therefore, at improving existing heterosexuals' social normative belief, cognition, and self-efficacy to promoting condom use are paramount to addressing the mirage of consequences associated with non or inappropriate use of a condom in Africa.

\section{Barriers to Condom Use}

Sarkar (2008) in a paper published using review, surveys, clinical studies, and comment data extracted between1993 and 2007 outlined some general factors associated with the non-use of a condom. This included cost alongside varying community variations like moral values, ethnicity, and religion. Other social factors such as gender inequality, lack of dialogue among partners about condom use, and the stigma attached to the condom could all lead to unprotected sexual intercourse. Personal factors such as aversion to the condom, consumption of alcohol or use of drugs before sexual intercourse, and anxiety and depression were all negatively associated with condom use, according to Sarkar (2008).

According to UNAIDS 2017 report, the end of term review of the 2010-2015 national HIV strategy identified condom uptake as having been a major area of challenge. The data identified cost, low availability and resistance to condom promotion from certain key religious and cultural groups as constituting the main barriers to the use of condom.

\section{Factors Fueling the Spread of HIV/AIDS in Africa}

Inungu and Sarah (2006) in their work towards understanding the Scourge of HIV/AIDS in Sub-Saharan Africa effectively brought to limelight the factors associated with the spread of the HIV epidemic in sub-Saharan Africa and so proposed 6 essential activities, which is denoted by the acronym "ESCAPER," to help curb the spread of HIV/AIDS in Africa. These implicating factors for HIV Spread include HIV-associated stigma, socioeconomic status, cultural and Traditional practices (polygamy and widow inheritance), STDs, migration \& forced labor, alcohol \& drugs, war \& conflicts, unsafe male circumcision practice, and female genital mutilation (FGM).

\section{HIV/AIDS treatment and prevention}

Even though HIV/AIDS yet has no cure it can still be treated or better still prevented (UNAID, 2019a). More so the only way to lessen the number of HIV/AIDS patients is to have some preventive strategies (Ngoma et al. 2015). There are different methods of HIV/AIDS prevention, and this can be achieved through behavioral, biological, and structural (relating to culture and environment). Generally, the most common strategies include: attempting to postpone the age at of first sexual debut, reducing the number of sexual partners/casual sexual partners, increasing the number of sexual protective activities, offering counseling and testing for HIV, encouraging adherence to biomedical approaches in avoiding HIV transmission, reducing sharing of sharp unsterilized objects such as needles, and syringes and decreasing substance use (Coates et al. 2008; Bekker et al. 2012). In the United States, some of the strategies are programmed to combat stigma and discrimination, increased open communication about sexual activities, multi- 
sectoral approaches, and STI surveillance and control (Douglas \& Fenton 2013; Satcher et al. 2015). In the United Kingdom, prevention programs for MSM, harm reduction, HIV awareness, and prevention programs for Africans who settle in the UK are some of their preventive strategies. In China, the prevention of infected blood donation and transfusion practices in place (Jamison et al. 2006). In the Pacific, there is optimal awareness, health education, and distribution of condoms in Hawaii, PNG, Vanuatu, Federated States of Micronesia, Fiji, Tonga, Samoa, and American Pacific Islanders (Kevany et. al. 2015).

Though there is no known cure for HIV/AIDS, it can still be preventable through appropriate focus group targeted health education, use of condoms, and effective antiretroviral drugs (ARVs) (WHO, 2019). The preventive effort, like condoms, when used the right way and every time, is highly effective in preventing HIV and other sexually transmitted diseases (STDs). Condoms are said to be 60 to 70\% effective when used for HIV prophylaxis, and when paired with other options like PrEP or ART, they provide even more protection (CDC, 2019 b; Pinkerton, Abramson, 1997). ARTs helped remarkably in the reduction of HIV infections by $37 \%$ and HIV-related deaths fell by $45 \%$, with 13.6 million lives saved due to ARVs (WHO, 2019). This achievement was the result of great efforts of the national HIV programs supported by civil society and international development partners (WHO, 2019).

In Africa, according to the WHO, 2010, preventive strategies advocacy is mainly condoms, prevention of mother-tochild transmission, voluntary medical male circumcision, harm reduction, and antiretroviral treatment. The same is generally true with Nigeria's Niger Delta except with the peculiar situation of cultural, environmental, and socioeconomic interplay that I intend to explore in this work.

\section{Health Care Barriers of HIV/AIDS Patients}

According to a systematic review work carried out by Mohammadnezhad et. al. (2017), out of 22 studies reviewed, 8 quantitative studies highlighted the barriers of HIV/AIDS among Pacific Islanders. The most common barriers reported were lack of accessibility to health services (3 studies, 37.5\%), followed by a lack of knowledge (2 studies, 25\%) (Mohammadnezhad et. al. 2017). The cultural taboos and ethnicity have been recognized as the least barriers among Pacific Islanders (1 study each) (Mohammadnezhad et. al. 2017). The most common barriers being cultural barriers (5 studies, 50\%), followed by access to health services (3 studies, 30\%) among Pacific Islanders, and the least barriers were racism and lack of sex education (1 study each) (Mohammadnezhad et. al. 2017).

\section{Theoretical Concepts for behavioral intervention}

From the review of literature, several models exist but a more holistic approach that shows all influences on a behavioral outcome is most desirable. An example of a streamlined model is the Information Motivation Model (IMB) that has been developed primarily in response to health behavior related to HIV/AIDS and condom usage (Fisher \& Fisher, 1992).

The Triadic influence theory (TTI) model has a more holistic and broader component, having constructs especially from the social and cultural-environment streams which are peculiar to the African situation (the assumed norm that engagement in unprotected sex is a sign and commitment of courtship and pregnancy is requirement for a marriage proposal). The TTI which is a relatively new but comprehensive theory integrates constructs from all previous theories (Flay, Snyder, \& Petraitis, 2009) that can address this risky emerging new behavior culture. The TTI includes 
seven "tiers" of "causes" of behavior that range from very proximal to distal to ultimate, and three "streams of influence" that flow through the seven "tiers" vis-à-vis (a) cultural- environmental influences on knowledge and values, influencing attitudes (b) intrapersonal influences on self-determination/control and social skills, leading to selfefficacy, and (c) social situation-context influences on social bonding and social learning, influencing social normative beliefs.

The IMB useful in skill motivation constructs and previous use of condoms (Mittal, M. et al. 2012) or the theory of planned behavior (TPB) useful when construct involving intimate partner violence (Abildso et al 2018), subjective norms, or rape (Manyaapelo et. al. 2017) are of interest.

Furthermore, the social marketing theory is very applicable in the context of policy development, program planning, implementation and practice as it relates to HIV prevention through the provision of condoms and its subsequent usage by at risk group. According to jhsph.edu, (2011) available evidence from rigorously evaluated interventions to prevent HIV transmission (meta-analysis research) social marketing theories is seen to be effective in promoting condom use in developing countries. In this study Condom social marketing (CSM) was seen to be a type of intervention in which condom brands are developed and marketed with a promotional campaigned targeted at a specific at-risk population (Jhsph.edu, 2011). The three main intervention components (CSM) been to inform condom branding, development of commodity logistic system and a sustained marketing campaign. ESCAPER put forward by Inungu \& Sarah 2006 addresses core barriers peculiar to sub-Saharan Africa that impact on the applicability and effectiveness of these various theories. Social marketing in its approach aimed at changing or maintaining people's behavior for the benefit of individuals and society as a whole, uses four Ps (Product, Price, Place and Promotion) model after the Marketing four in designing programs (Goldberg et al. 1997). According to Social Marketing Report, this is defined as, "the application of commercial marketing techniques to social problems" (Goldberg et al. 1997). Some programs where social marketing has been used successfully include the following 1. A campaign to promote the well-being of children and youth in the greater Kansas City area, 2. The Kansas Health Foundation's (KHF) Children's Effort: Creating the Best Place in the Nation in Which to Raise a Child, 3. Salud te Recomendia (meaning health recommends you)- Puerto Rico 4. MTV "Staying Alive"; Ignite Kenya SHUGA-Kenya, 5. Reaching Out to Communities at Risk of Ebola in Liberia, and 6. Snap and Click, Colorado Department of Transportation.

\section{Social Marketing Implementation Strategies}

$1 \quad$ Engage potential partners and change agents

2 Analyses the key related behavior and environmental problems or goals

$3 \quad$ Identify components or strategies

4 Select and tailor components base on urgency, burden and feasibility

$5 \quad$ Pretest and revise in pilot before full implementation

6 Implement the social marketing

$7 \quad$ Evaluate

8 Sustainability

Page $10 / 21$ 


\section{Types of Condoms and Special Concern}

There is currently a more popular condom type simply called the "male condom" worn by the male partner and the less popular one worn by the female partner called "femidom" (CDC, 2019b). They are made from a variety of materials: Latex (common), Plastics (Polyurethane), Rubber, Lambskin (Not protective), Nitrile (Female condom), and Silicone (a prospect).

\section{Strategies to prevent HIV/AIDS}

According to Inungu and Sarah 2006 below are effective ways (ESCAPER) to curb HIV/AIDS in sub-Saharan Africa:

Educate

Know your HIV Status

Care for the marginalized and those who are infected

Train effective Personnel to staff and manage HIV prevention programs

Empower people and encourage self-efficacy

Banish harmful Rituals and instead promote love and justice

\section{Research Methodology}

The study aims to identify barriers to condom use among heterosexuals in Africa and thus explore measures to effectively curbing the HIV menace. This is carried out using the Niger Delta case study. This is choosing following the currently reported prevalence by the Nigeria National Agency for the Control of AIDS (NACA). The report details were as contained in the Nigerian HIV/AIDS Indicator and Impact Survey (NAIIS) report which stated that" about one percent of Nigerians (1.9 million people) are currently living with HIV/AIDS. The South-south zone (Niger Delta) of the country has the highest HIV prevalence, at 3.1 percent among adults (UNAID, 2019b). This is aside from other age groups, including children (see Table $i$ and ii).

\section{Study Area}

The study was carried out using Nigeria's Niger Delta as a case study. This Sub-Saharan Africa subregion, according to the Niger Delta Development Commission (NDDC) Nigeria webpage, seats on the Gulf of Guinea and neighboring the Atlantic Ocean and serves as the delta of the River Niger. The Niger Delta is a densely populated region generally considered to be inclusive of nine Southern Nigerian coastal states. The entire of the six south-south states of Akwa Ibom, Bayelsa, Cross River, Delta, Edo and Rivers State, and two states from the south-east (Abia and Imo) and then one state (Ondo) from the South-west geopolitical zone. Officially, defined by the Nigerian government to extends over about 70,000 km2 (27,000 sq. mi), and makes up 7.5\% of Nigeria's landmass. It has a population of about 31 million people, comprising of more than 40 ethnic groups, including Bini, Efik, Esan, Ibibio, ljaws, Igbo, Ikwerre, Itsekiri, Isoko, Urhobo, Ogoni, and Obolo ethnic nationalities. Speaking about 250 language dialects. There is a unique tradition of the people which are expressed in various cultural masquerades and dances. The people of the Niger Delta are 
predominately Christians, believing in the existence of one Supreme Being. Others practice traditional worshipping. The region is endowed with abundant mineral oil and forest resources with its people being predominately farmers, fishermen, and traders of food items such as palm oil and other palm produce, vegetables, banana, yam, cassava, and seafood.

\section{Study population and sampling and Data collection tool}

The study population consisted of sexually active heterosexuals' adults in the Niger Delta region of Nigeria. The inclusion criteria included: Being a medical doctor in the subregion with at least 2 years of community medical practice experience; having completed a rotation in the HIV clinic; being indigenous to the subregion. Non-stakeholder of the region and other health worker cadres were excluded from the study. The focus group was created using a convenient snowballing technique involving doctors in the region.

Data were collected through an online focus group discussion format, comprising of 10 medical doctors who were considered experienced and opinionated following medical practice in the subregion.

\section{Inclusion criteria}

1. Medical Doctor

2. Practice in the Niger Delta region

3. Experience with HIV/AIDS Care

\section{Exclusion criteria}

1. Non-Medical Doctor

2. Non-experience with HIV/AIDS care

\section{Informed Consent/ Ethical consideration}

Verbal and written consent was stated by the participating medical doctors at the start of the discussion session. Other ethical clearance was also considered as related to expert opinion data sharing of experience in practice.

\section{Results}

Table iii. Demographic Characteristic description of the focus group 


\begin{tabular}{|ll|}
\hline DEMOGRAPHIC CHARACTERISTIC OF PARTICIPANTS & FREQUENCY (PERCENTAGE) \\
\hline Age & $0(0 \%)$ \\
$25-34$ years & $10(100 \%)$ \\
$35-45$ years & $0(0 \%)$ \\
$>45$ years & \\
Sex & $7(70 \%)$ \\
Male & $3(30 \%)$ \\
Female & $10(100 \%)$ \\
Years of Clinical Experience in the region & $2(20 \%)$ \\
$>5 y e a r s$ & $7(70 \%)$ \\
State of practice & $1(10 \%)$ \\
South East geopolitical zone (Abia and Imo States) & \\
South South geopolitical zone & \\
(Akwa Ibom, Bayelsa, Cross River, Delta, Edo) & \\
South west geopolitical zone (Ondo State) & \\
\hline
\end{tabular}

The outcome of the focus group discussion (Table iii) brought to limelight several important findings. This includes ; 1 That sexual relationship in the subregion is mainly heterosexual, 2 . The average age range for a first sexual debut is between 14 to 22 years for females, and 15 to 22 years for males. The age range for sexual engagement lies between 14 and as late as 60 years and women tending to stop earlier than males. The earlier the age at first sexual debut the more likely barriers to using condoms sets in, and this goes the same with living in rural areas. At the end of the focus group discussion, twelve (12) Elements were identified as barriers to the use of condoms. They include;

\section{Poverty}

Poverty was a crucial factor opinionated to have served as a barrier. This is seen especially on the part of the female who hardly has an equal opportunity when compared to a male's counterpart in the community. This makes them vulnerable and unable to negotiate for the safe use of condoms. Poverty on the part of the males makes them unable to purchase or even transport themselves to the local chemist shop to get one. Destruction of means of livelihood by recurrent environmental oil pollution as well as a high rate of unemployment was said to have worsened the poverty situation.

\section{Low and uneven distribution of knowledge and awareness.}

It was generally opinionated that knowledge and awareness were unevenly distributed, with the urban communities having more informed awareness on condom use via more access to public health intervention than their rural community counterparts. Even at that, the general awareness is still considered to be at an unaccepted low level in the region.

\section{Negative perception}


It was put forward that a negative perception of condoms exists, seen both on the part of the male and female gender. That condoms constitute an artificial sex object that steals away the naturalness of sex. Also, seen as a sign of promiscuity. Most were of poor quality and seldom burst during sexual activity making it unreliable for use. Another is the perception that there was no need for a condom if the partner has already been engaging in unprotected sex with a known partner or trusted partner.

\section{Motivational barriers}

Lack of knowledge and skill on how to use condoms was said to be a demotivation, especially for young male teenagers.

\section{Partner-related factors}

The intention to hook up a man with pregnancy for marriage on the part of the female is seen to present a serious barrier to the use of condoms. It was recounted that female partners will hide condoms whenever in the middle of a sexual act with a targeted male partner. The male partner without a strong will may go in the act without the use of condoms. The same was recounted to applies to the females who are pressurized by male partners into showing evidence of fertility before marital rites are performed. It was stated also that in some instances, conditions of condom latex allergy were an excuse for negotiating non-use of condoms with male partners by females. The attractiveness of the female partner was another dimension stated to influence the decision of not using a condom.

\section{Access/availability barriers}

It was noted that stigma and difficulties associated with accessing and non-availability of condoms in the communities presented barriers to the use of condoms by those who may have wanted to use one. Especially for unmarried individuals' residents in rural communities that usually may have just one chemist store or a health center.

\section{Religious factors}

Mostly said to have been observed amongst members of the Roman Catholic faithful, who advocates for sexual abstinence and deferment of sex until after marriage. But no clear message on condom use in any other instance.

\section{Early age at first sexual debut}

This was stated to be more associated with risky sexual habit and unplanned sex thus use of condoms in this age group were reportedly low.

\section{Alcohol and substance}

The use of alcohol and drugs pre or during sex was stated to pose barriers to safely negotiating and using condoms.

\section{Intimate partner violence arising from gender inequality}

This again was sighted as a limitation to condom use. The male partner is the culprit here. Following the dominant nature of male partners in the region. Some female partners experience pressure and sexual violence.

\section{Cultural Beliefs and social stigma}

They believe that HIV/AIDS is inflicted by witchcraft especially amongst some ethnic individuals also serve as barriers in some part of the region. This serves as an obvious barrier to condom use. 
This was stated as one of the more common causes of nonuse of condoms by those who have the awareness but due to an accidental happening. Like tear of condom during the sexual act itself, or not having condoms on them.

\section{Discussion}

This study aimed at identifying barriers to condom use among heterosexuals in the Niger Delta region and thus explore measures to effectively curb the HIV menace, using the Niger Delta region of Nigeria as a case study. Twelve elements emanating from possible perceptions, attitudes, sexual practices, or beliefs that could act as barriers to protective behavior. Six essential activities simply refer to by the acronym "ESCAPER" proposed by Inungu, J., \& Karl, S. (2006) were used as a guide in drawing conclusions towards a solution, for the subregion and elsewhere.

It must be stated that the use of collective expert opinions from the subregion helped in giving a point in time summary of the common barriers to condom use in the region. Though, this may not be free from some sources of bias like information bias and recall bias.

There exist some similar studies on barriers to condom use, however, the approach of looking at these barriers from the perspective of indigenous experts' opinions is unique. Especially, a holistic view in response to the recently reported HIV/AIDS prevalence of 3.1 in the subregion. Again, most studies did not go on to suggesting practical intervention solutions that can be applied. This work brought to limelight barriers relating to poverty, low and uneven distribution of knowledge and awareness, negative perception, motivational barriers partner-related factors, access/availability barriers, religious factors, early age at first sexual debut, alcohol and substance use, intimate partner violence, cultural believes and accidental casual sex.

This however did not contradict any earlier work. However, Udoh (2013) in his work found that the Niger Delta region HIV/AIDS epidemic is exacerbated by recurring regional conflict and negative environmental externalities resulting from over 50 years of oil exploration. This observation as well as barriers posed by pollution and other environmental stressors in Nigeria's Niger Delta were seen to pose a serious challenge to control effort in the subregion. So, rightly these barriers come from a multi-stream of influences that centers on the behavioral situation and grassroots health intervention program impact situation.

Limitations and likely source of bias to this study were notably that of recall bias on the part of the expert respondents. The data collection method has certain limitations for being from an online forum. However, internal validity was strengthened through the use of indigenous expert participants. This participation also provided an opportunity for a sort of round table discussion and deliberation on the HIV/AIDS scourge in the region, hence, reigniting concerns and call for action. The discussion ended with suggestions on pragmatic solutions, and urgent needs for further research, siting of an Internationally backed public health institute, and designing of a theory driven system thinking on long-term program on condom use and other HIV/AIDS prevention intervention in the subregion.

\section{Pragmatic solutions}

Pragmatic solutions to these research findings on barriers to condom use amongst heterosexuals in the Niger region and by extension Africa entails the recommendations below; (and should ideally cut across relevant stake holders of the community). This will include women, youths, religious groups, traditional institutions, civil society organizations, employers of labor, educational institutions, and government (federal, state, local and tribal). 


\section{Recommendations}

1. Adopting the Sustainable Development Goals (SDGs) blueprint in terms of policy formulations, implementation, and practice for effective delivery of all essential health services in the region as a towards reducing additional infections, morbidity, and mortality from HIV/AIDS.

2. A new paradigm shift in the effort through a System thinking-backed HIV/AIDS prevention and care theory-driven program designed that integrates voices, needs, and priorities of everybody in a community. The most vulnerable communities and at-risk populations in Africa accorded the desired attention.

3. Adopting the recommendation of the acronym ESCAPER and addressing its findings in terms of policies development, when designing a program, when choosing a theory-backed intervention for HIV/AIDS prevention, and in public health practice in Sub-Saharan Africa.

4. Uninterrupted monitoring, evaluation, and updating all ongoing HIV/AIDS prevention programs in the subregion and addressing these revealed barriers.

5. Direct and focused theory-driven yearly behavioral change intervention program on young graduates at the start of National Youth Service Corps (NYSC)-orientation and at completion (pass out) of NYSC service. This should be for every batch and through Public-Private Partnership (PPP) in collaboration with the Federal Ministry of Health, NYSC, National Health Insurance Scheme, MDAs, all relevant Governmental and Non-Governmental Agencies.

6. Establishment of HIV/AIDS youth friendly \& prevention centers across the 36 States and FCT of Nigeria.

7. Provision of free and accessible condoms to health centers, communities, and schools.

8. Establishment of the center for Disease outbreaks Universities or Research institutes.

9. Establishment of HIV/AIDS prevention centers for developing countries, rural and underserved communities in Universities like Central Michigan University.

10. More research and funding on HIV/AIDS prevention and care.

\section{Conclusion}

Findings from this study demonstrated the salient need for implementing behavioral health intervention programs alongside the provision of public health measures. Promoting HIV/AIDS control measures such as using condoms will required a well-designed health intervention targeting the community as well as the individuals. Awareness alone is not enough unless it translates into behavioral change and control. HIV/AIDS prevention advocacy is likely to suffer setbacks as it is right now until heterosexual couples fully understand the use of condoms as a primary preventing measure. Promoting healthy behaviors requires subtle and effective behavioral change programs. The programs should tackle different aspects of human life including our personality, social, cultural, and environmental factors.

\section{Declarations}

Funding

Page $16 / 21$ 
No funding was received for this work

Ethical approval

This was not applicable as work was considered exempted by the participating clinician ethical center review consideration as opinion contribution.

\section{Conflict of Interest}

The authors declare no competing interests

Informed Consent

Oral and written consent was obtained from the contributary clinicians as they shared their opinions

Data, Materials and/or Code availability Sharing

Not applicable

Authors contribution

DNE conceived and carried out the study under the supervision of JI, TMA and MJM,

Acknowledgement

The authors acknowledge that this work arose from academic research carried out at the Central Michigan University, USA. The authors express their gratitude to the Central Michigan University department of public health (faculty and staff) and all authors of cited references. Gratitude to all the participants and also to Noeilie Marie Aurore Guezo for her contribution during the focus group session as moderator.

\section{References}

Abildso, C. G., Dyer, A., Kristjansson, A. L., Mann, M. J., Bias, T., Coffman, J., Vasile, E., \& Davidov, D. (2018). Evaluation of an Intimate Partner Violence Training for Home Visitors Using the Theory of Planned Behavior. Health promotion practice, 19(2), 194-202. https://doi.org/10.1177/1524839917728050

Autenrieth, C. S., Beck, E. J., Stelzle, D., Mallouris, C., Mahy, M., \& Ghys, P. (2018). Global and regional trends of people living with HIV aged 50 and over: Estimates and projections for 2000-2020. PloS one, 13(11), e0207005. https://doi.org/10.1371/journal.pone.0207005

Ayoola, O. D., Victoria, G. O., Bamidele, O., Olufela, K. O., Oluwatosin, S. E., Mbaneifo, E. P., Titilola, G., Adagu, A. R., Ifeanyi, O. D., Harry, O., Oluwatosin, O., Nonyelum, O. N., Nkiruka, D., \& Chukwujekwu, E. O. (2014). Pattern, challenges and correlates of condom use among Nigerians living with HIV infection. Asian Pacific journal of tropical biomedicine, 4(Suppl 1), S198-S203. https://doi.org/10.12980/APJTB.4.2014C1003

Bekker, L. G., Beyrer, C., \& Quinn, T. C. (2012). Behavioral and biomedical combination strategies for HIV prevention. Cold Spring Harbor perspectives in medicine, 2(8), a007435. https://doi.org/10.1101/cshperspect.a007435

Center for Disease control (CDC) (2006). Evolution of HIV/AIDS Prevention Programs--United States, 1981-2006. Retrieved from https://www.cdc.gov/mmwr/preview/mmwrhtml/mm5521a4.htm. 5/4/2020 
Center for Disease control (CDC), (2019). National Center for HIV/AIDS, Viral Hepatitis, STD, and TB Prevention. Trends in the prevalence of sexual behavior and HIV testing National YRBS: 1991-2015. Retrieved from http://www.cdc.gov/healthyyouth/data/yrbs/pdf/trends/2015_us_sexual_trend_yrbs.pdf. 5/4/2020

Center for Disease control (2019b). Condoms. Retrieved from https://www.cdc.gov/hiv/risk/condoms.html Center for Disease control (2021). Condom Effectiveness. Retrieved on 12/14/2021 from https://www.cdc.gov/condomeffectiveness/brief.html

Coates, et. al.(2008). Behavioural Strategies to Reduce HIV Transmission: How to Make Them Work Better. The Lancet, 372, 669-684. https://doi.org/10.1016/S0140-6736(08)60886-7

Cohen, et al. (2008). "The spread, treatment, and prevention of HIV-1: evolution of a global pandemic". The Journal of Clinical Investigation. 118 (4): 1244-54. doi:10.1172/JCI34706. PMC 2276790. PMID 18382737.

Deeks, S. G., Lewin, S. R., Ross, A. L., Ananworanich, J., Benkirane, M., Cannon, P., Chomont, N., Douek, D., Lifson, J. D., Lo, Y. R., Kuritzkes, D., Margolis, D., Mellors, J., Persaud, D., Tucker, J. D., Barre-Sinoussi, F., International AIDS Society Towards a Cure Working Group, Alter, G., Auerbach, J., Autran, B., ... Zack, J. (2016). International AIDS Society global scientific strategy: towards an HIV cure 2016. Nature medicine, 22(8), 839-850. https://doi.org/10.1038/nm.4108

Deniaud F. Actualité du préservatif féminin en Afrique (Current status of the female condom in Africa). Sante. 1997;7(6):405-415.

Douglas, J. M., Jr, \& Fenton, K. A. (2013). Understanding sexual health and its role in more effective prevention programs. Public health reports (Washington, D.C.: 1974), 128 Suppl 1(Suppl 1), 1-4.

https://doi.org/10.1177/00333549131282S101

Fisher and Fisher (1992). Changing AIDS-risk behavior Psychological Bulletin, 111 (3) (1992), pp. 455-474 http://dx.doi.org/10.1037/0033-2909.111.3.455

Fisher, Jeffrey D. and Fisher, William A. (2000). Theoretical Approaches to Individual-Level Change in HIV Risk Behavior. Accessed from https://opencommons.uconn.edu/cgi/viewcontent.cgi?article=1003\&context=chip_docs. $5 / 4 / 2020$

Flay, Brian \& Petraitis, John. (1994). The Theory of Triadic Influence: A New Theory of Health Behavior With Implications for Preventive Interventions. Advances in Medical Sociology. 4. 19-44.

Flay, B. R., Snyder, F. J., and Petraitis, J. (2009). The Theory of Triadic Influence. In R. J. DiClemente, R. A. Crosby and M. C. Kegler (Eds.), Emerging Theories in Health Promotion Practice and Research (Second ed., pp. 451-510). San Francisco, CA: Jossey-Bass.

Goldberg, M., Fishbein, M., Middlestat, S. (Eds.) (1997). Social marketing: Theoretical and practical perspectives. Washington, D.C.: The Academy for Educational Development.

Hiv.gov (2020). Global HIV/AIDS Overview. Accessed from https://www.hiv.gov/federal-response/pepfar-globalaids/global-hiv-aids-overview. 7/20/2020

Inungu, J., \& Karl, S. (2006). Understanding the Scourge of HIV/AIDS in Sub-Saharan Africa. Journal of the International AIDS Society, 8(1), 30. https://www.scirp.org/journal/paperinformation.aspx?paperid=73100 
Jamison, et al. (2006). Disease Control Priorities in Developing Countries. World Bank Publications.

Jhsph.edu (2011). Research to prevention. Retrieved from

https://www.jhsph.edu/research/centers-and-institutes/research-to-prevention/publications/csm.pdf

Kevany, S., et. al. (2015). Global Health Diplomacy, National Integration, and Regional Development through the Monitoring and Evaluation of HIV/AIDS Programs in Papua New Guinea, Vanuatu, and Samoa. International Journal of Health Policy and Management, 4, 337-341. https://doi.org/10.15171/ijhpm.2015.89

Kharsany, A. B., \& Karim, Q. A. (2016). HIV Infection and AIDS in Sub-Saharan Africa: Current Status, Challenges and Opportunities. The open AIDS journal, 10,34-48. https://doi.org/10.2174/1874613601610010034

McKenzie, Neiger, Thackeray (2016). Planning, Implementing \& Evaluating Health Promotion Programs: A Primer. Pearson Education.

Manyaapelo, T., Nyembezi, A., Ruiter, R. A., Borne, B. V., Sifunda, S., \& Reddy, P. (2017). Understanding the Psychosocial Correlates of the Intention to Use Condoms among Young Men in KwaZulu-Natal, South Africa. International journal of environmental research and public health, 14(4), 339.

https://doi.org/10.3390/ijerph14040339

Mathers, C. D., \& Loncar, D. (2006). Projections of global mortality and burden of disease from 2002 to 2030. PLoS medicine, 3(11), e442. https://doi.org/10.1371/journal.pmed.0030442

Mirriam-webster 2014. https://www.merriam-webster.com/thesaurus/sexual\%20intercourse

Mittal, M., Senn, T. E., \& Carey, M. P. (2012). Intimate partner violence and condom use among women: does the information-motivation-behavioral skills model explain sexual risk behavior?. AIDS and behavior, 16(4), 1011-1019. https://doi.org/10.1007/s10461-011-9949-3

Mohammadnez-had, M., Alakalia, J.Q., Mangum, T., Fetuu, F.P. and Lucas, J. J. (2017) Barriers and Strategies to Prevent HIV/AIDS among Pacific Countries: A Systematic Review Study. Advances in Sexual Medicine, 7, 20-33. http://dx.doi.org/10.4236/asm.2017.71002

M. Ngoma, C. , Roos, J. and Siziya, S. (2015). Knowledge about HIV and AIDS among Young Women. Open Journal of Nursing, 5, 558-565. https://doi.org/10.4236/ojn.2015.56059

Niger Delta Development Commission (NDDC). Retrieve from https://www.nddc.gov.ng/. 5/1/2020

Ntshiqa, T., Musekiwa, A., Mlotshwa, M., Mangold, K., Reddy, C., \& Williams, S. (2018). Predictors of male condom use among sexually active heterosexual young women in South Africa, 2012. BMC public health, 18(1), 1137. https://doi.org/10.1186/s12889-018-6039-8

Ogden, L., Shepherd, M., Smith, W. (1996). Applying prevention marketing. Atlanta, GA: Centers for Disease Control and Prevention, Public Health Service. Order a free copy by calling the National AIDS Clearinghouse at (800) 4585231. Request publication D905.

Paz-Bailey, G., Noble, M., Salo, K., \& Tregear, S. J. (2016). Prevalence of HIV Among U.S. Female Sex Workers: Systematic Review and Meta-analysis. AIDS and behavior, 20(10), 2318-2331. https://doi.org/10.1007/s10461-016- 
Reynolds, H. W., Luseno, W. K., \& Speizer, I. S. (2012). The measurement of condom use in four countries in East and southern Africa. AIDS and behavior, 16(4), 1044-1053. https://doi.org/10.1007/s10461-012-0146-9

S. D. Pinkerton, P. R. Abramson (1997). Effectiveness of condoms in preventing HIV transmission Soc Sci Med. 1997 May; 44(9): 1303-1312. https://doi.org/10.1016/S0277-9536(96)00258-4

Sarkar N. N. (2008). Barriers to condom use. The European journal of contraception \& reproductive health care: the official journal of the European Society of Contraception, 13(2), 114-122.

https://doi.org/10.1080/13625180802011302

Satcher, D., et. al (2015). Sexual Health in America: Improving Patient Care and Public Health. JAMA, 314, $765-766$. https://doi.org/10.1001/jama.2015.6831

Sandøy, I. F., Michelo, C., Siziya, S., \& Fylkesnes, K. (2007). Associations between sexual behaviour change in young people and decline in HIV prevalence in Zambia. BMC public health, 7, 60. https://doi.org/10.1186/1471-2458-7-60

Sandøy, I. F., Blystad, A., Shayo, E. H., Makundi, E., Michelo, C., Zulu, J., \& Byskov, J. (2012). Condom availability in high risk places and condom use: a study at district level in Kenya, Tanzania and Zambia. BMC public health, 12, 1030. https://doi.org/10.1186/1471-2458-12-1030

Sovran S. (2013). Understanding culture and HIV/AIDS in sub-Saharan Africa. SAHARA J : journal of Social Aspects of HIV/AIDS Research Alliance, 10(1), 32-41. https://doi.org/10.1080/17290376.2013.807071

Udoh, I. A. (2013). Oil, Migration, and the Political Economy of HIV/AIDS Prevention in Nigeria's Niger Delta. International Journal of Health Services, 43(4), 681-697. https://doi.org/10.2190/HS.43.4.f

Udoh, I. A., Mantell, J. E., Sandfort, T., \& Eighmy, M. A. (2009). Potential pathways to HIV/AIDS transmission in the Niger Delta of Nigeria: poverty, migration and commercial sex. AIDS care, 21(5), 567-574.

https://doi.org/10.1080/09540120802301840

UNAIDS (2015). UNFPA, WHO and UNAIDS: Position statement on condoms and the prevention of HIV, other sexually transmitted infections and unintended pregnancy. Accessed

from https://www.unaids.org/en/resources/presscentre/featurestories/2015/july/20150702_condoms_prevention. $5 / 4 / 2020$

UNAIDS (2016). Joint United Nations Programme on HIV/AIDS. Accessed from http://www.unaids.org/sites/default/files/media_asset/global-AIDS-update-2016_en.pdf -https://doi.org/10.1371/journal.pmed.0030442

UNAIDS (2019a). HIV Prevention. Accessed from https://www.unaids.org/en/topic/prevention 5/4/2020

UNAID (2019b). Press Release. Retrieved on 12/14/2021 from

https://www.unaids.org/en/resources/presscentre/pressreleaseandstatementarchive/2019/march/20190314_nigeria UNAIDS (2020). Global HIV \& AIDS statistics-2020 fact sheet. Accessed from https://www.unaids.org/en/resources/fact-sheet 9/30/2020 
UNAID (2021). Condom Use Declining. Retrieved on 12/14/2021 from

https://www.unaids.org/en/resources/presscentre/featurestories/2020/november/20201123_condom-use-declining UNICEF (2021). HIV/AIDS-Global regional trend. Retrieved on 12/14/2021

from https://data.unicef.org/topic/hivaids/global-regional-trends/

World Health Organization (2010). Towards Universal Access: Scaling up Priority HIV/AIDS Interventions in the Health Sector. Retrieved from https://www.who.int/hiv/pub/2010progressreport/en/ 5/4/2020

World Health Organization (2019). HIV-AIDS. Retrieved on 12/14/2021 from https://www.who.int/news-room/factsheets/detail/hiv-aids 